\title{
EMPLOYMENT CONTRACTING UNDER THE ECA: PRELIMINARY SURVEY RESULTS
}

\author{
Craig Armitage \\ Industrial Relations Service \\ Department of Labour
}

\begin{abstract}
In order to make an initial assessment of the extent of labour market adjustment under the Employment Contracts Act 1991, the Department of Labour commissioned surveys of adjustment under the Act in 1992 and 1993 . These surveys showed the spread of enterprise bargaining and individual employment contracts, the nature of industrial relations changes made in different types of enterprises, and the concentration of changes amongst larger enterprises. The surveys also demonstrated that many of the changes made under the Act occurred in its initial years. The Department has commissioned a similar survey again this year, the final results of which are due early next year. This paper explains the objectives of this year's survey, how it differs from the previous surveys, and presents some preliminary results.
\end{abstract}

New Zealand's labour market had been undergoing a process of reform during the 1980 s which had centred on the removal of State intervention and the shifting of responsibility for workplace outcomes on registered employer and employee representatives. These reforms came in several steps. Compulsory arbitration was removed in 1984. In 1987 the introduction of the Labour Relations Act sought to further decentralise bargaining in the private sector. The State Sector Act 1988 applied most of the industrial relations arrangements in the private sector to the public sector for the first time. Despite these labour market reforms, the performance of the labour market and the rather slow movement to enterprise based bargaining provided the catalysts for the comprehensive labour market changes made in the early 1990s. 1

The Employment Contracts Act was enacted in May 1991. The stated objective of the Act was to improve the adaptability of enterprises in their competitive marketplaces. The Act did this by giving employers and employees choices to make about representation and bargaining.

\section{First survey, 1992}

The introduction of the Employment Contracts Act (ECA) saw the end of registered awards and agreements. As a result, many of the previously existing information sources available to the Department of Labour for monitoring negotiation trends disappeared. ${ }^{2}$ To meet these monitoring requirements, the Industrial Relations Service of the Department of Labour invited tenders for a national survey of labour market adjustment. The Heylen Research Centre and Teesdale Meuli \& Co. were commissioned to conduct the survey in May 1992.
The objective of the survey was to identify 'adjustment' under the ECA, that is, to assess the degree and the way in which employees and employers were making decisions about freedom of association (collective organisation) and bargaining (both collective and individual). The 'adjustments' of interest were changes in collective organisation and collective and individual contract coverage before and after the ECA, and between earlier surveys and the latest survey as well as the bargaining process itself. The research focused in particular on the representation and negotiation choices underpinning the Act. Quantitative data was sought on bargaining structures, outcomes and representation taking into account the varying sizes of industries, enterprises and regions. Qualitative data was sought on bargaining issues and productivity. These objectives led to data being collected under six broad headings: employment contract structures; the bargaining process; employment contract and bargaining outcomes; productivity changes; and attitudes and opinions of employees and employers, which included their view of remaining barriers to adjustment.

The project was divided into two stages. Firstly, a qualitative investigation was undertaken in the form of case studies and key participant interviews were conducted. This helped to identify the range of issues to be covered. Secondly, a quantitative stage was based on three separate surveys of employees, enterprises and directors. Small enterprises (<4 employees) and non-trading central and local government organisations, and their employees and directors were excluded. A random sample of enterprises, stratified by industry, enterprise size and location, was drawn by the Department of Statistics and a self-completion questionnaire mailed to them. 1000 employees were randomly selected from the telephone directory. Only those who were in the same job now as in May 1991 were included. 500 
directors were randomly selected from the Business Who's Who. Details of the survey method and questionnaire design were subject to scrutiny and approval by the Government Statistician. In short these first surveys we were interested in the degree to which enterprises had moved away from the award system, into new employment contract structures and arrangements directly related to the operation of their organisation.

\section{Second survey, 1993}

In June 1993 the Department of Labour decided to repeat the survey but with a broader focus. All Government enterprises with 4+ employees were included in the sample population. Only producer-enterprises were included the previous year. The employee survey was expanded to be fully comprehensive including all employees. The previous year only those in producer-enterprises with 4+ employers who had not changed jobs for one year were included. Additional questions also covered important issues on training provision and expected recruitment difficulties. The survey of directors was not repeated. The sample size for the employee survey was increased from 1000 to 2000 to provide for more reliable analysis of sub-groups such as by gender.

These surveys showed the spread of enterprise bargaining and individual employment contracts, the nature of industrial relations changes made in different types of enterprises, and the concentration of changes amongst larger enterprises. The surveys also demonstrated that many of the changes made under the Act occurred in its initial years.

\section{Third survey, 1996}

The Department's continued need for much of the information provided by the previous surveys led to the proposal to repeat these surveys again in 1996. Information gaps became particularly obvious in relation to employees with individual employment contracts, and the impact this may have on the minimum code of employment and the Industrial Relations Service's operations.

Expressions of interest and then tenders were sort for the project in April/May 1996, and Colmar Brunton Research were contracted to conduct the survey project.

While the third survey was initially to be a repeat of the previous surveys, some changes were proposed. It was proposed for example to delete sections of the questionnaires gathering information on employees' and employers' opinions of the Employment Contracts Act. More recent surveys have shown little change in opinion on this issue.

It was also proposed to ask new questions relating to the extent of reliance on the minimum code of employment and the Industrial Relations Service's service delivery role. The increasing prevalence of individual employment contracts and decrease in the size of the organised workforce has led to an increased workload for the Labour Inspectorate. The extension of further individual employment rights to the entire labour force has also contributed to the Inspectorate's workload, and that of the Employment Tribunal. Information additional to that captured by the IR Service's management information systems was required.

Qualitative research and draft questionnaire piloting also saw other changes to the previously used questionnaires. The degree to which employers could be expected to provide detailed information about their employees was found to be limited in a self-completion questionnaire format, and thus detailed questions asking employers about changes in their employees' terms and conditions of employment were not included. Different bargaining processes for different types of contractual change were reported, and thus questions on bargaining process were split into three sections on negotiations over new (different) contracts, negotiations to renew existing contracts, and negotiations that were incomplete or unsuccessful.

\section{Methodology}

Two separate surveys were conducted in 1996, an Employee Survey and an Enterprise Survey. They were conducted during August and September.

Samples for the employee and enterprise surveys were drawn independently, employees were selected randomly from the telephone directory. All employees were eligible and 2000 were interviewed.

Enterprises are separate business or service entities operating in New Zealand such as a company, partnership, trust, estate, Incorporated Society, Producer Board, Local or Central Government Organisation, Voluntary Organisation or self-employed individual. Only enterprises identified as having 4 or more employees were included in the survey because of the disproportionate burden and less relevance of the survey questionnaire to very small enterprises. These enterprises covered only seven percent of employees.

Enterprises included in the survey were divided into two groups; 'Public Sector'; this includes all local and central government enterprises excluding trading enterprises. SOEs are therefore excluded as are commercial activities of local government. Included were all the different government departments administrative staff and all public sector health and education enterprises including hospitals and schools; and, 'Private Sector'; this includes all private trading companies and the trading activities of central and local government (this includes SOEs). Also included were the private sector non-profit organisations such as churches and voluntary associations.

A random sample of 4000 enterprises was selected by Statistics NZ on our behalf ( 800 Public and 3200 Private) and self-completion questionnaires mailed to them. The previous questionnaires were used as the basis for developing new questionnaires. Samples were weighted and stratified to both reduce cost and improve accuracy.

Respondents were sent reminder letters with additional questionnaires, and those that had still not responded were 
contacted by Statistics NZ by telephone on our behalf, reminded to respond, and where an indication was given that they were unlikely to respond, were faxed a short version of the questionnaire (8 questions, $\sim 5$ minutes), which they could then fax back when completed.

The survey was conducted in a manner consistent with the Department of Labour's guidelines on the running of statistical surveys. Detailed survey objectives and survey plans were drafted, specialist subject matter, statistical and questionnaire expertise were consulted, and all proposals were approved by a steering committee. Survey plans were subject to Statistics NZ scrutiny, and the enterprise survey plan required their approval before a sample from the Business Directory could be drawn. The Department maintained regular reporting and monitoring links with Colmar Brunton as the project progressed.

\section{Preliminary results}

Only some preliminary, raw (unweighted) survey results were available as of November 1996 . While they may give an indication of the final results in many cases, firm conclusions should not be drawn from them. Final, weighted results will be available when the final report is published early in 1997.

\section{Response rates}

The nature, size, and complexity of these surveys made response rates a major concern. The project initially aimed to produce estimates that would be generalisable to the population as a whole (at least $65 \%$ response rate), although we were aware that most recent non-compulsory surveys of a similar nature had struggled to achieve these levels. Considerable attention was therefore paid to methods by which non-response could be reduced.
The telephone survey of employees produced an estimated response rate of $42 \%$. Particular problems were encountered with the survey's timing, coinciding with a plethora of telephone political polls. The survey of enterprises produced an estimated response rate of $50 \%$, of which half were full questionnaires sent by mail and half were shortened questionnaires sent by fax by respondents unwilling to complete the full questionnaire. These response rates mean the final data will not be generalisable to the population as a whole, and can only be viewed as the responses of 2000 randomly selected employees and 1800 randomly selected enterprises.

\section{Contract structures}

One of the main findings of the earlier surveys conducted on behalf of the Department of Labour was the confirmation of the impact of the ECA in terms of a move towards enterprise based bargaining. Preliminary results from the 1996 survey certainly do nothing to change this impression (see Figure 1 ), although in their raw form they do indicate a level of collective bargaining higher than that suggested by anecdotal evidence (see Figure 2). The survey did over-sample the public sector and larger firms, where collective bargaining is reportedly more common, and so once these figures are weighted appropriately, the level of collective bargaining is likely to drop. The results of the employee survey however, also indicates higher than expected levels of collective bargaining (see Figure 3).

The degree to which the responses of employers and employees agree also make interesting reading. The most noticeable difference in their answers about employment contract types comes in the proportions indicating coverage by informal or unwritten contracts or contracts based on expired awards or collectives. Whereas employers indicated that about $10 \%$ of their employees were in this category, about $24 \%$ of employees reported they were covered by such

Figure 1. Private sector employment contract structures 1991-1996

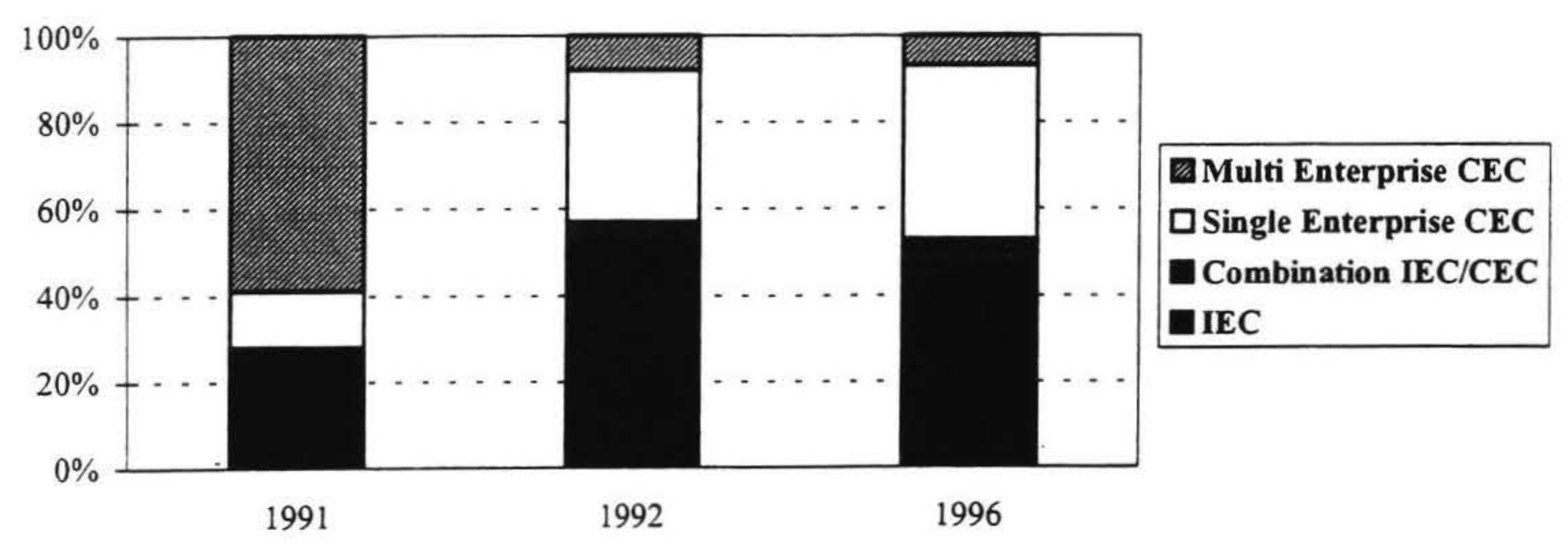


Figure 2. 1996 employment contract structures

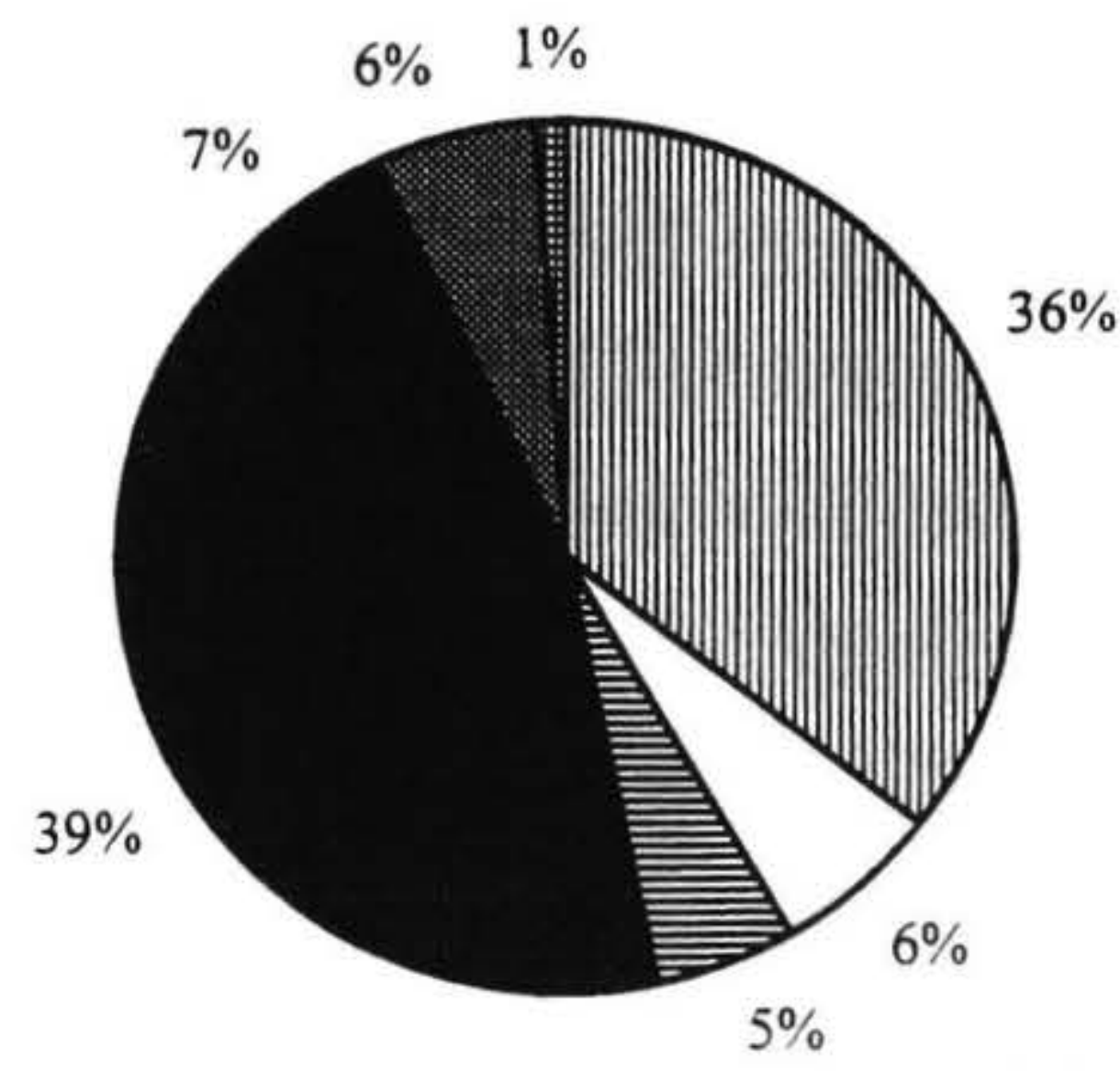

m Written IEC
$\square$ Unwritten IEC
E Expired CEC/ Award
Single Employer CEC
Multi Employer CEC
Combined CEC/IEC
WDon't Know

Base: All Private Sector Employees. Enterprise Survey (unweighted data)

contractual arrangements. Even allowing for the unweighted data, and a margin of error, this would, at least initially, seem to be a significant difference. It would seem likely that for some employees, even if their terms and conditions of employment have been put into writing at some point, they are not aware of or do not recall seeing them.

The degree to which employers and employees distinguish between different forms of employment contract is an area for concern from the perspective of industrial relations survey information. The distinction between an individual employment contract which an employee signs on an individual basis without much discussion, and a collective employment contract which an employee signs individually without much discussion is difficult to see from any perspective other than a legal one. The same could be said of the difference between a group of employees electing a bargaining team to negotiate their standard individual employment contracts with their employer and a similar team negotiating a collective employment contract.

Union membership as a measure of collective organisation is similarly inaccurate, as many union members may be covered by individual employment contracts some or most of the time, and many groups of employees organise themselves or are organised in some way short of formal trade union membership. While information about employment contract structures do serve to give an indication of movements between individual, enterprise, and multi-employer bargaining, more detailed information is required about the negotiation process and form, particularly representation and the extent of negotiation, to make any assessment of the key drivers of change in bargaining.

\section{Bargaining process}

Both enterprises and employees were asked about their experiences in negotiating employment contracts. Approximately $17 \%$ of enterprises and $45 \%$ of employees had not been involved in negotiations over an employment contract in the previous 12 months. Of those who had, $32 \%$ of enterprises and employees had negotiated new employment contracts (contracts significantly different to those applying previously). Just over $50 \%$ of enterprises and employees had negotiated renewed employment contracts (substantially similar to those applying previously), while less than

Figure 3. 1996 employee contract type

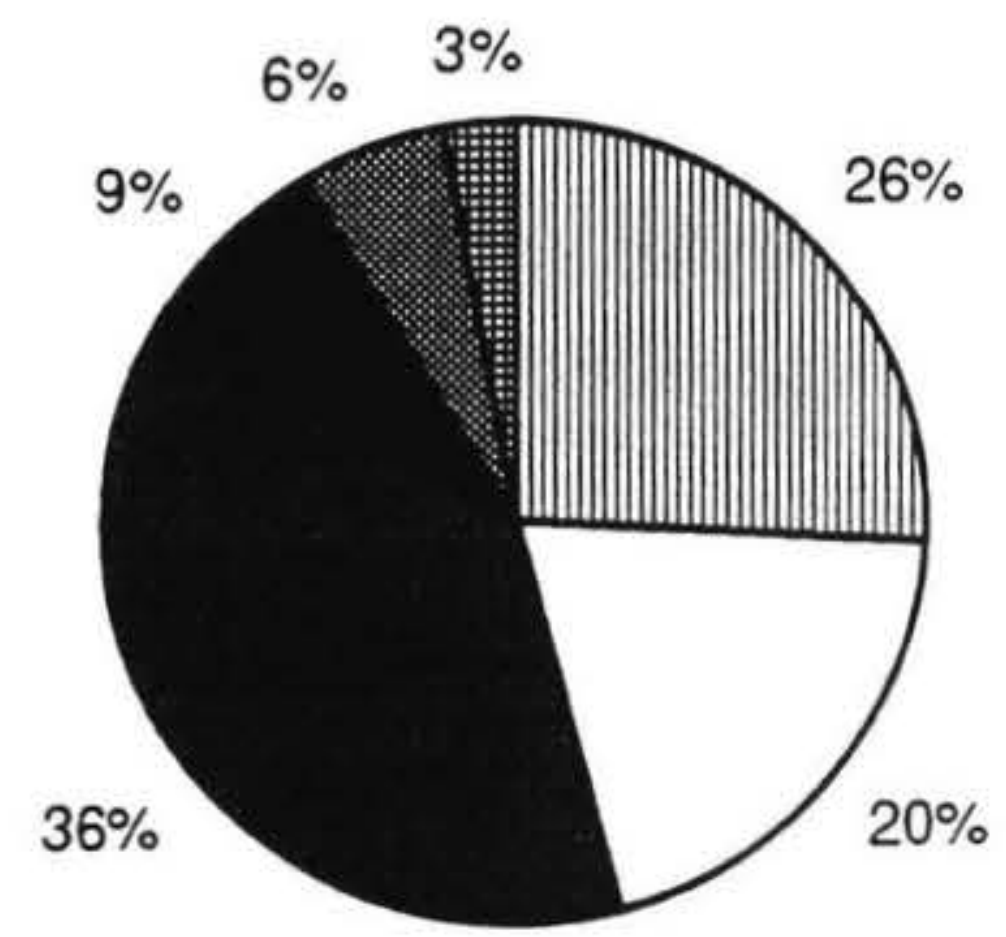

\begin{tabular}{|l|}
\hline ⿴囗W \\
$\square$ Unwitten IEC \\
Single Employer CEC \\
Multi-Employer CEC \\
ख Combination IEC/CEC \\
⿴囗十 Other \\
\hline
\end{tabular}

Base: All employees in same main job, Employee Survey (unweighted data) 
$5 \%$ had been involved in unsuccessful negotiations for employment contracts. Approximately $9 \%$ of enterprises and $20 \%$ of employees were in the midst of incomplete negotiations for employment contracts.

For enterprises and employees who reported no involvement in negotiations over employment contracts in the previous 12 months, both groups were most likely to report, when asked why, said that there was no need to make any changes to employment contracts during the year. Employees under individual employment contracts were less likely to have been involved in contract negotiations in the previous year.

As per the findings of previous surveys, the majority of employees who negotiated individual employment contracts represented themselves, while the majority of employees under collective employment contracts were represented by a trade union (overall, $33 \%$ of employees indicated they were a member of a trade union, a higher figure than many other recent estimates would suggest). Employers were most likely to represent themselves using local, on-site management.

Small numbers of respondents indicated that while they had settled new or renewed employment contracts, no negotiations had taken place. Most of these respondents indicated that the new or renewed contracts were simply offered and accepted, or that no negotiations were needed as the contract did not make great changes to terms and conditions of employment. The small number of respondents who indicated that they had had unsuccessful negotiations were most likely to mention disagreements over pay increases or other terms and conditions of employment as the reason the negotiations had been unsuccessful.

\section{Contract outcomes}

While collective employment contracts are required by statute to contain an expiry date, there is no such requirement for individual employment contracts. While the norm has been for individual employment contracts to be open-ended, there has been anecdotal evidence suggesting the proportion of fixed term individual contracts has increased. Approximately $31 \%$ of new IECs reported by enterprises are fixed term, while $39 \%$ of renewed IECs had fixed terms. Twelve month terms were most common (see Figure 4). The presence of a fixed term in an employment contract does not necessarily mean the employee's employment is for a fixed term, as in increasing number of contracts contain an expiry date indicating an opportunity for review, or sometimes renegotiation, rather than automatic termination (overall, $9 \%$ of employees considered themselves to be casual, and $14 \%$ had more than 1 job). ${ }^{3}$ For example, enterprises were instructed to include employees on one-off, fixed term employment contracts that were not going to be renewed as casual employees (employees on repeatedly rolled-over term contracts were recorded as permanent full-time or parttime), and only reported $11 \%$ of their employees were casual, $14 \%$ as permanent part-time ( $<30$ hours per week) and $75 \%$ as permanent full-time.

With respect to changes to other terms or conditions of employment, employees were most likely to report that their overall take-home pay had gone up, while the total hours worked, leave entitlements, health and safety provisions, and redundancy entitlements were most likely to have stayed the same (see Figure 5). Approximately half the employee respondents indicated they had never had any child-care provisions with their job. A minority (10-20\%) of employees thought they had never had any entitlement to sick/ family/special leave, or to parental leave.

\section{Disputes and grievances}

Respondents were asked about their experience of individual disputes and grievances in the workplace (not bargaining disputes such as strikes or lockouts). $21 \%$ of enterprises and $10 \%$ of employees reported that they had experienced at least one dispute or grievance at work in the previous 12 months. Enterprises reported disputes and

\section{Figure 4. IEC terms}

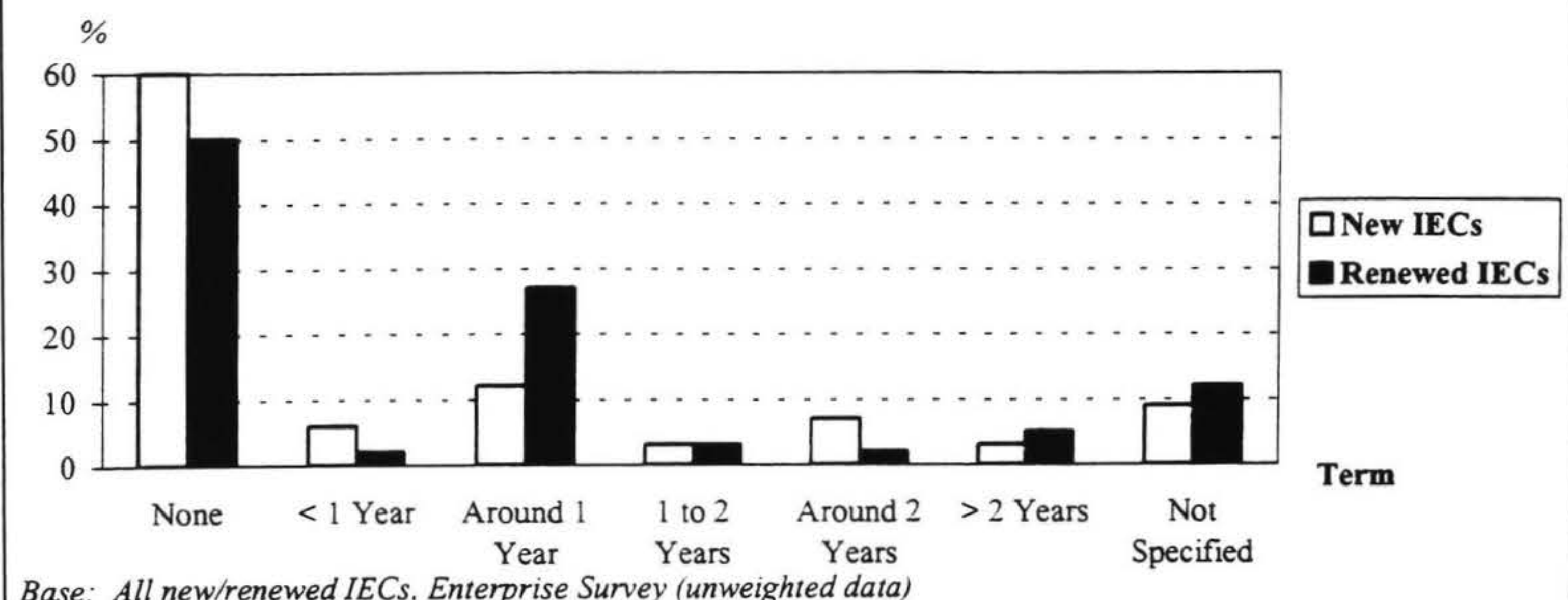

Base: All new/renewed IECs. Enterprise Survey (unweighted data) 
Figure 5. Changes to employment conditions

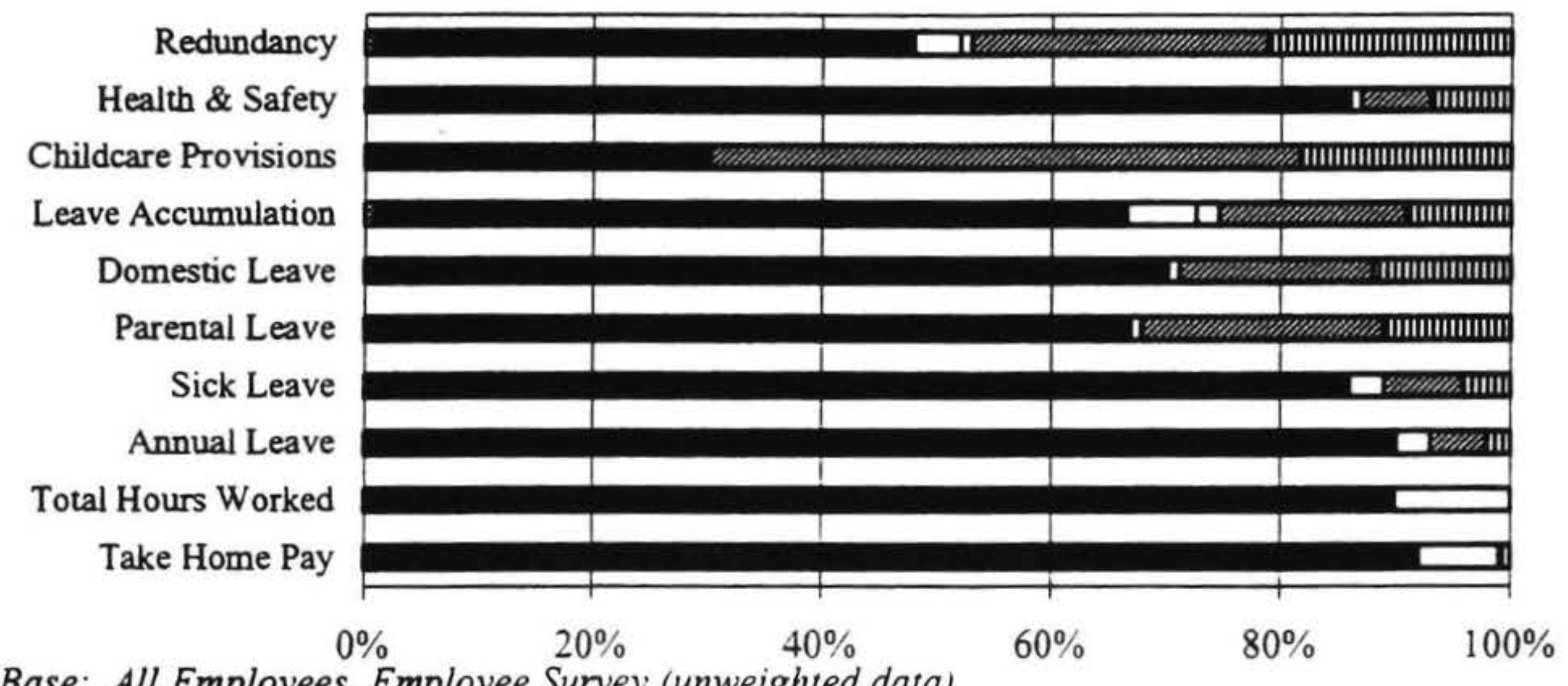

\begin{tabular}{|l|}
\hline mon't Know \\
m Never Had \\
$\square$ Abolished \\
$\square$ Down \\
Same \\
$\square$ Up \\
Introduced \\
\hline
\end{tabular}

Base: All Employees. Employee Survey (unweighted data)

grievances relating to performance or discipline as being most common, while employees reported disputes or grievances about the payment of wages as being most common.

Enterprises which had experienced disputes or grievances were most likely undertake internal discussion, mediation, or negotiation or to take disciplinary action (other than dismissal) as an initial response to a dispute or grievance. In situations where disputes or grievances remained unresolved after initial steps had been taken, enterprises were as likely to seek independent mediation as they were to suggest going to the Employment Tribunal.

\section{Awareness of the minimum code}

Without prompting, employees were asked what minimum terms and conditions of employment are set by Government legislation. Only adult minimum wages were mentioned by any great number $(32 \%)$ of employees without prompting. When employees were prompted, over three quarters of them said they thought adult minimum wages, annual holidays, safe and healthy work places, and public holidays were provided for in legislation. Two thirds of employees thought that notice for dismissal or resignation, and meal breaks were prescribed by legislation when in fact they are not. Only approximately $50 \%$ of employees were aware of a youth minimum wage, and only around $60 \%$ of employees were aware there were minimum sick and bereavement leave entitlements set by statute (see Figure 6). The Department of Labour and Trade Unions were the most commonly mentioned sources of advice on minimum employment conditions mentioned by employees.

\section{Enterprise size}

Previous surveys undertaken on behalf of the Department of Labour indicated considerable differences in the responses to the Employment Contracts Act made by different sized firms. Earlier surveys indicated smaller firms were much less likely to have made changes or negotiated new employment contracts in the early years after the Act's introduction.

Once again, it would appear that small firms are far less likely to have been involved in negotiations for new or renewed employment contracts. They are far less likely to have employees covered by collective employment contracts, and are much more likely to have employees covered by unwritten contracts or contracts based on expired awards or collectives. Figure 7 shows employment contract type by size of firm.

\section{Conclusion}

The preliminary results of the 1996 survey indicate that most of the structural adjustment that has occurred under the ECA occurred in its initial years. The initial patterns of enterprise collective and individual employment contracts that appeared in 1992 and 1993 do not seem to have altered to a significant extent, although the degree to which employers and employees distinguish between different forms of employment contract is an area for concern from the perspective of industrial relations survey information.

It is likely that a more detailed picture will emerge of more recent changes under the Act once a more detailed analysis of the bargaining process information collected by the sur- 


\section{Figure 6. Awareness of the minimum code of employment}

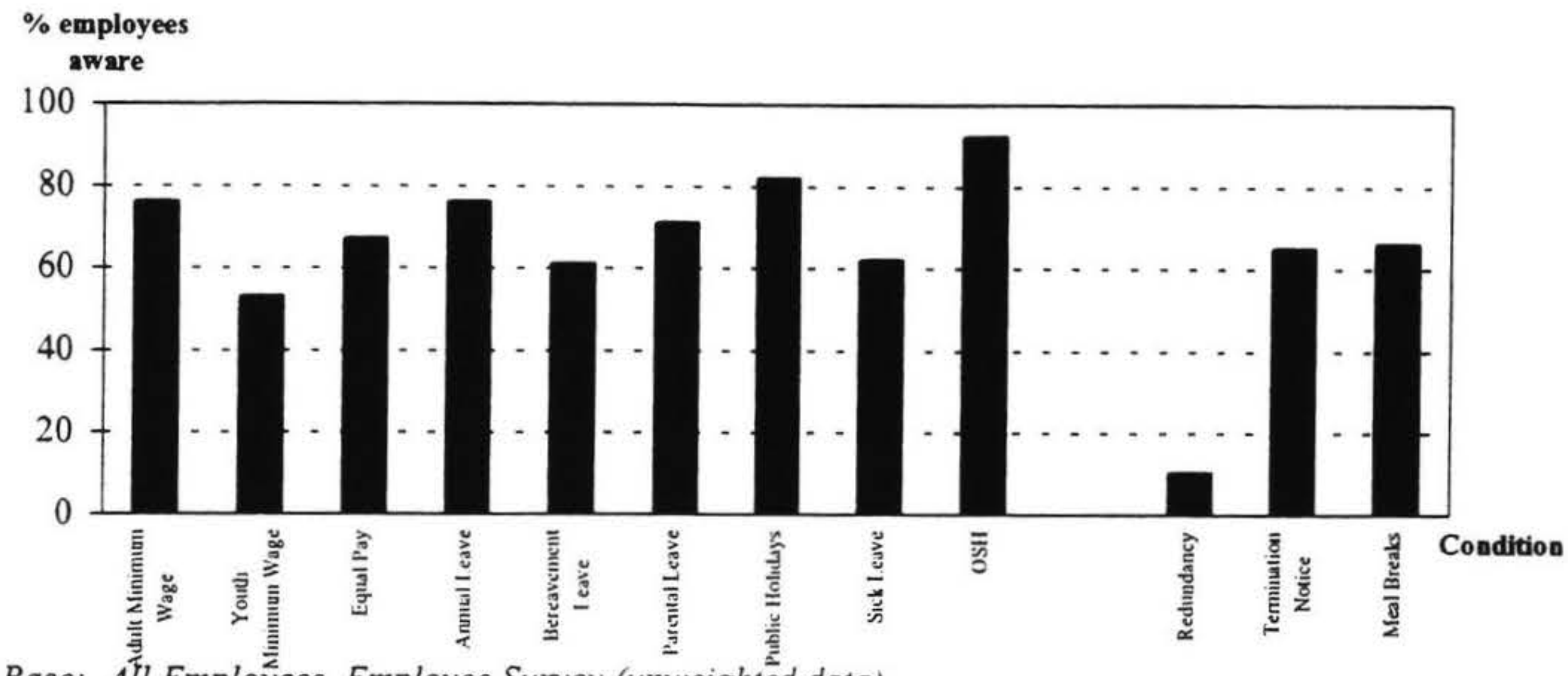

Base: AIll Employees. Employee Survey (unweighted data)

vey is made. The previously reported patterns of individual (for IECs) and trade union (for CECs) representation continued. The most common bargaining experiences involved the renewal of existing employment contracts.

Fixed term employment contracts have become quite common, although most do not appear to affect employees' permanent employee status. Between 30 and $40 \%$ of IECs reported by enterprises are fixed term. When enterprises were instructed to include employees on one-off, fixed term employment contracts that were not going to be renewed as casual employees (employees on repeatedly rolled-over term contracts were recorded as permanent full-time or parttime), however, only reported $11 \%$ of their employees were casual, the other $89 \%$ being permanent employees.
Employees awareness of their statutory employment rights appears quite variable, particularly with regard to sick/ special leave and youth minimum wages. Most employees thought terms and conditions such as set notice periods and meal breaks were an automatic legal entitlement for all employees, despite the fact that they are not set in statute.

Finally, once again, it would appear that small firms are far less likely to have been involved in negotiations for new or renewed employment contracts. This is not simply a function of their size, as they are much more likely to have employees covered by unwritten contracts or contracts based on expired awards or collectives.

\section{Figure 7. Contract type by enterprise size}

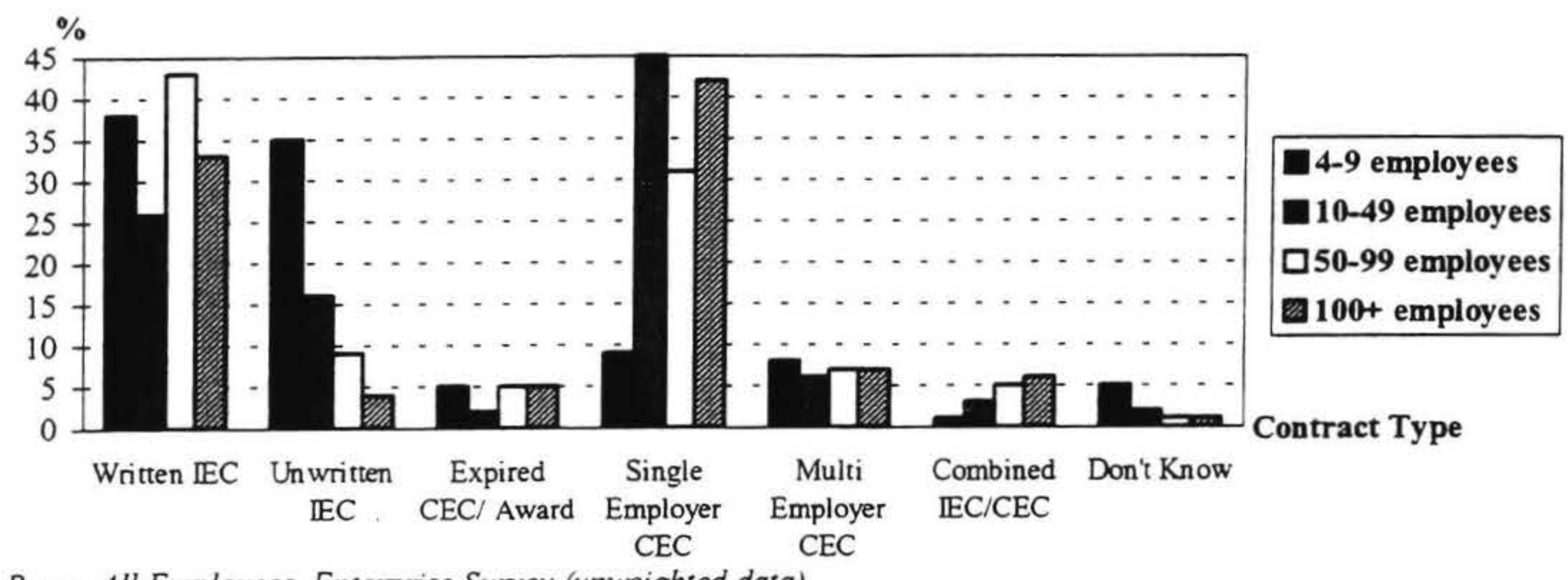

Base: All Employees, Enterprise Survey (unweighted data) 


\section{Future research}

A final report on this survey project, which will include a more detailed analysis of all the results, as well as a detailed methodological summary, is expected to be published in 1997.

The difficulties with response rate and question complexity for such a large, ad-hoc survey of industrial relations and related issues, raises a number of questions about their appropriateness and effectiveness in the future. Whether this leads to the conclusion that a semi-regular, more detailed and comprehensive collaborative industrial relations survey, such as a WIRS or an AWIRS, would be the most effective way of improving the information base for industrial relations research, or whether the conclusion is made that a series of smaller scale, more focused surveys, interviews and case studies, perhaps on an enterprise, industry, or case study basis, in conjunction with national Statistics NZ data, would be more effective and practical, will undoubtedly be the subject of considerable thought and debate.

\section{Notes}

1. Although some changes in bargaining structures had resulted from the industrial relations reforms of the $1980 \mathrm{~s}$, by 1990 most employees were still covered by national multi-employer awards related in some way to occupation, and most employers were covered by more than one of these awards (McAndrew, 1992: 261).

2. See Armitage \& Dunbar (1992: 95).

3. For the purposes of this survey, casual was defined as: "hired on a periodic basis as the need arises with no on-going expectation of employment".

\section{References}

Armitage, C, \& Dunbar, R. 1993 Labour market adjustment under the Employment Contracts Act New Zealand Journal of Industrial Relations 18(1): 94-112.

Department of Labour 1992 A survey of labour market adjustment under the Employment Contracts Act Department of Labour, October, Wellington.

Department of Labour 1993 A survey of labour market adjustment under the Employment Contracts Act Department of Labour, November, Wellington.

McAndrew, I. 1992 The structure of bargaining under the Employment Contracts Act New Zealand Journal of Industrial Relations 17(3): 259-282.

Whatman, R, Armitage, C, \& Dunbar, R. 1994 Labour Market Adjustment under the Employment Contracts Act New Zealand Journal of Industrial Relations 19(1): 53-73.

\section{Author}

Craig Armitage is a Policy Advisor with the Industrial Relations Service of the Department of Labour, P O Box 3705, Wellington. He was the Project Manager for the survey described in this paper. 